\title{
A RARE CASE OF STERNAL EROSION DUE TO BRONCHOGENIC CARCINOMA
}

\author{
Sudipta Pandit ${ }^{1}$, Anirban Das ${ }^{1}$, Sibes K. Das ${ }^{1}$, Sabyasachi Choudhury ${ }^{1}$, \\ Somnath Mukherjee ${ }^{2}$
}

\begin{abstract}
BACKGROUND: Primary sternal malignancy is very uncommon. Secondary sternal malignancy is usually caused by either hematological dissemination or by direct extension due to parasternal lymph node involvement from breast or lung carcinoma.

CASE DETAILS: A 72 years old smoker presented with a dull aching pain over the sternum. Computed tomography $(C T)$ of the thorax revealed osteolytic erosion of manubrium sterni, along with a mass of lesion in the upper lobe of left lung and left sided mediastinal lymphadenopathy. CT guided fine needle aspiration cytology (FNAC) of the left lung mass showed squamous cell carcinoma and FNAC of the sternal lesion revealed metastatic squamous cell carcinoma.

CONCLUSION: Direct erosion of sternum in case of squamous cell carcinoma of lung is a rarity. We have reported this case to increase the awareness of clinicians regarding the possibility of direct sternal involvement from lung cancer. Moreover, local removal can improve the prognosis.

KEYWORDS: Sternal erosion, Lung cancer, Local spread
\end{abstract}

DOI: http://dx.doi.org/10.4314/ejhs.v24i1.12

\section{INTRODUCTION}

Primary tumours of the sternum are rare $(0.6 \%-$ $1 \%$ ), and most of them are malignant (1). Two thirds of sternal masses are metastatic (2). Metastatic tumours often come from breast, lung, kidney and thyroid gland while direct invasion of the sternum often occurs from lymphoma, bronchogenic carcinoma, breast cancer, pleural and mediastinal malignancy (2). The skeleton is a common site of metastasis in lung cancer. The lesions are usually osteolytic and often present with severe bone pain. However, the sternal involvement either due to loco-regional spread or by distant metastasis from lung cancer is very rarely reported. We report a case of loco-regional spread to sternal body in a patient of lung cancer to increase the awareness of the physicians and oncologists.

\section{CASE REPORT}

A 72 years old normotensive, non-diabetic male smoker presented with dull aching pain in the upper anterior chest wall adjacent to sternum, along with cough with scanty, white, mucoid expectoration for one month. His night sleep was disturbed due to severe chest pain which was not relieved by non-narcotic analgesic. He also complained of a gradually progressive hoarseness of voice for fifteen days. He had a history of anorexia and a significant weight loss, but there was no history of hemoptysis or dyspnoea. No past history of pulmonary tuberculosis was present either.

On general survey, he had pallor, clubbing, and left sided supraclavicular lymphadenopathy. His axillary temperature, respiratory rate, pulse rate and blood pressure were $36^{\circ} \mathrm{C}, 16$

\footnotetext{
${ }^{7}$ Department of Pulmonary Medicine, Medical College, Kolkata, West Bengal, India

${ }^{2}$ Department of General Medicine, Medical College, Kolkata, West Bengal, India

Corresponding Author: Sudipta Pandit, Email: drsudiptapandit@rediffmail.com
} 
breaths/minute, 100 beats/minute and 110/80 $\mathrm{mmHg}$ respectively. On examination of respiratory process, the chest was acutely tendered in the left infraclavicular area and in sternal region, but no mass was palpable. Percussion note over left second and third intercostal spaces near parasternal area and over sternum was dull. Complete hemogram, blood biochemistry and urinalysis proved normal. Sputum smear for acid fast bacilli and malignant cells was negative. Chest X-ray (posteroanterior view) showed left sided para-hilar mass with irregular margin. Contrast enhanced computed tomography (CECT) of the thorax showed a soft tissue mass in the left upper lobe with variegated appearance and irregular margin without any calcification, associated with left sided mediastinal lymphadenopathy and osteolytic erosion of left half of the manubrium sterni (Figure 1). Radioisotope bone scan using Technetium $-99 \mathrm{~m}$ $\left({ }^{99 \mathrm{~m}} \mathrm{Tc}\right)$ labeled methylene diphosphonate (MDP) showed sternal deposit without the involvement of other bones. Ultrasound of abdomen was also normal. Fibreoptic bronchoscopy (FOB) showed no endobronchial lesion and bronchoalveolar (BAL) lavage fluid revealed no acid fast bacillus or malignant cell. Fine needle aspiration cytology (FNAC) of left supraclavicular lymphadenopathy showed metastatic squamous cell carcinoma. CTguided FNAC of the left lung mass showed dispersed clusters of malignant epithelial cells with squamous differentiation and cytoplasmic keratinization in the background of inflammatory cells (Figure 2). CT-guided FNAC of sternal lesion yielded a similar cytology. Hence, final diagnosis was squamous cell carcinoma of left lung with sternum and mediastinal plus cervical lymph node metastases. The patient was advised for cytotoxic chemotherapy comprising of cisplatin and etoposide, but unfortunately, he succumbed to his illness before initiation of first cycle of chemotherapy.

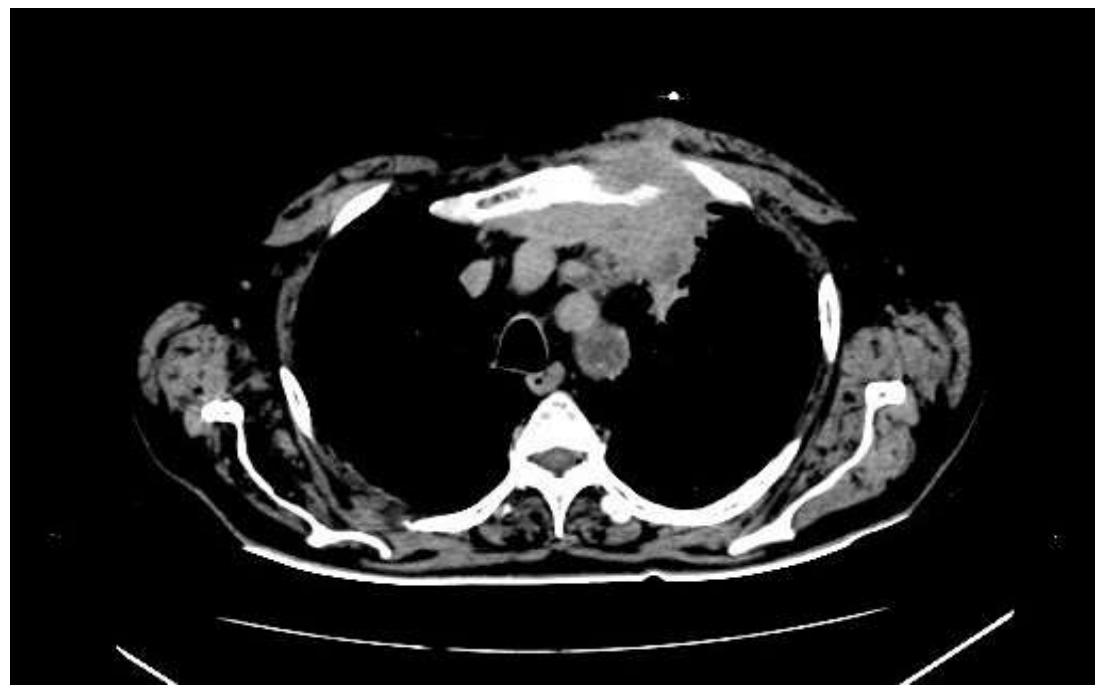

Fig. 1: CECT thorax showing left upper lobe mass with erosion of manubrium sterni

\section{DISCUSSION}

Bone is the commonest site of metastasis from a primary cancer, and $80 \%$ of metastases arise from breast, lung, prostate, kidney, and thyroid gland 3). The axial skeleton is usually affected possibly due to the vertebral-venous plexus and the slow blood flow in the axial skeleton 4). Common sites of bony metastases are vertebrae, spine, pelvis and ribs 5). Isolated sternal metastasis is rare due to lack of vascular communication with the paravertebral plexus since venous drainage of the sternum is not through the paravertebral plexus. Isolated sternal metastasis by hematogenous spread from renal, colorectal, hematological and hepatic malignancy is described. $(7,9)$. However, it is also rarely reported in association with lung cancer $(7,10)$. Most of the sternal involvements are due to loco-regional extension of the adjacent tumour like breast cancer (11). Sternal spread may occur directly from the adjacent neoplasm or from the parasternal lymph node involvement (11). 


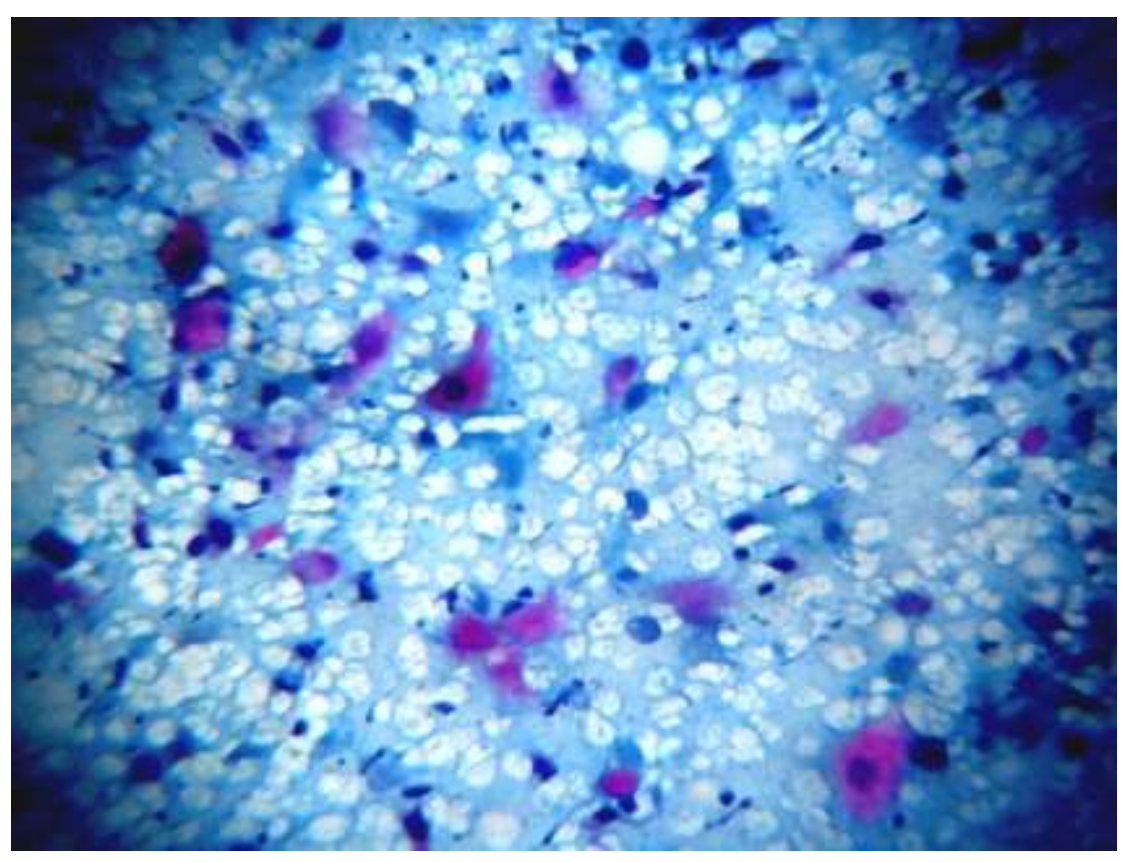

Fig. 2: Photomicrograph of FNAC of left lung mass showing squamous cell carcinoma (x400, MGG stain)

Bone involvement in lung cancer occurs either by direct extension into adjacent bones like ribs, sternum, thoracic vertebrae, or by hematogenous spread as in humerus, or lumber vertebra (12). Pathologically, the patients with localized rib involvement constitute $\mathrm{T} 3$ on the basis of seventh edition TNM staging system for lung cancer; so staged as stage IIB or IIIA (13). Isolated sternal metastasis constitutes stage IV (13). But in both the situations, surgery is a possible option for loco-regional treatment, thus sternal involvement either by local spread, or hematogenous metastases is prognostically better compared to distant bone metastases (2).

Clinically, secondary sternal malignancy is usually asymptomatic (3). Bone pain may be present in $10 \%$ cases (14). The commonest sign is palpable mass (14), sometimes associated with bleeding (12). Chest X-ray often reveals the osteolytic lesions. However, other causes of sternal erosion like thoracic aortic aneurysm, sternal surgery, infectious mediastinitis, sternal tuberculosis, or rheumatoid arthritis should be excluded. ${ }^{99 \mathrm{~m}} \mathrm{Tc}$ bone scan is the most costeffective screening test for assessment of bone metastasis. Isotope imaging depicts metastatic bone lesions as areas of increased uptake. However, other patterns like normal scans, photopenic lesions, flare phenomenon etc. are also possible (15). Lesions are better delineated by CT scan of the thorax and magnetic resonance imaging (MRI) of the sternum (5). CT scan is useful in guiding needle biopsy of the lesion. However, it is insensible in showing small intramedullary lesions. It is also unsuitable as a screening tool because of high radiation dose. MRI can detect malignant lesions before it is detectable with bone scans (16). MRI is helpful in determining the extent of local disease before planning surgery or radiotherapy. Metastatic lesions are seen as areas of hypo density on $\mathrm{T} 1$ images and areas of intermediate or high signal intensive on T2 images. Positron emission tomography (PET) scan can identify bone metastasis at an early stage before host reaction to osteoblasts occurs. In a comparative study of three modalities, the sensitivities of PET scan, whole body MRI and isotope scan were $90 \%, 82 \%$ and $71 \%$ respectively (17). Sternal malignancy is treated either with curative radiotherapy or with total or partial sternectomy followed by reconstructive surgery with myocutaneous flap (serratus anterior, latissimus dorsi) and prosthetic mesh (marlex, stainless steel mesh, teflon, nylon, acrylic, tantalum, polypropylene and vicryl nets, Gore-Tex patch) $(7,18)$. Reconstructive surgery must be done with a rigid material as it prevents paradoxical movement of the thorax during 
respiration and provides stability of the chest wall and protection of intra-thoracic organ (8). Sternal metastasis as a part of disseminated disease should be treated with systemic chemotherapy (18). Newer or emerging moralities of treatment of bone metastasis include bone seeking radiopharmaceuticals (BSR) like ${ }^{89}$ strontium, ${ }^{153}$ samarium and ${ }^{186}$ rhenium, prophylactic therapy with bisphosphonates and denosumab, a human antibody targeting RANK-L (19). In our case, as metastases occurred in cervical and mediastinal lymph nodes, localized treatment of isolated sternal metastasis was not possible; therefore, systemic chemotherapy was planned. But, unfortunately, the patient succumbed to the disease before the initiation of the therapy.

Secondary sternal tumours from lung primaries occur due to direct invasion or by hematogenous dissemination. But isolated sternal tumour in lung cancer is a rarity. It can be detected by radionuclide bone scan, and diagnosis is confirmed by CT-guided FNAC. Partial or complete resection of the sternal tumour followed by reconstruction with prosthetic materials improves the prognosis.

\section{REFERENCES}

1. Douglas YL, Meuzelaar KJ, van der Lei B, Pras B, Hrekstra HJ. Osteosarcoma of the sternum. Eur $J$ Surg Oncol, 1997; 23:90 - 1 .

2. Darbari A, Tandon S. Unusual sternal mass: adenocarcinoma with unknown primary site. Ann Thorac Med, 2006; 1:84 - 6.

3. Jacofsky DJ, Frassica DA, Frassica FJ. Metastatic disease to bone. Hospital Physician, 2004; 39:21 28.

4. Ball E, Morris-Stiff G, Coxon M, Lewis MH. Mucinous adenocarcinoma presenting as an isolated sternal metastasis. World $J$ Surg Oncol, 2007; 5:105.

5. Oliver TB, Bhat R, Kellett CF, Adamson DJ. Diagnosis and management of bone metastases. $J$ $R$ Coll Physicians Edinb, 2011; 41:330 - 8.

6. Kim H, Huh SJ, Park W, Choi DH, Kang MK, Yang JH, et al. Results of three-dimensional conformal radiation therapy for the treatment of a solitary sternal relapse of breast cancer. J Korean Soc Ther Radiol Oncol 2008; 26:91 - 5.

7. Toussirot E, Gallinett E, Auge B, Voillat L, Wendling D. Anterior chest wall malignancies. A review of 10 cases. Rev Rheum, 1998; 65:397 405.

8. Haraguchi S, Yamashita Y, Yamashita K, Hioki M, Matsumoto K, Shimizu K. Sternal resection for metastasis from thyroid carcinoma and reconstruction with the sandwiched Marlex and stainless steel mesh. Jpn J Thorac Cardiovasc Surg, 2004; 52:209 - 12.

9. Batista RR, Marchiori E, Takayassu TC, Cabral FC, Cabral RF, Zanetti G. Sternal metastasis as an initial presentation of renal cell carcinoma: a case report. Cases J, 2009; 2:9045.

10. Bachmeyer C, Langman B, Kazerouni F, Charoud A, Mougeot-Martin M. Inflammatory sternal metastasis heralding lung cancer: two cases. Clin Rheumatol, 2006; 25:409 - 11.

11. Lee L, Keller A, Clemons M. Sternal resection for recurrent breast cancer: a cautionary tale. Curr Oncol, 2008; 15:193 - 5.

12. Trujillo - Reyes JC, Rami - Porta R, Barreiro López B, González - Minguez C, Aliagad LC, Belda - Sanchís J. Lung adenocarcinoma presenting as a bleeding sternal mass. Open $J$ Thorac Surg, 2012;2: 15.

13. Lababede O, Meziane M, Rice T. Seventh edition of the cancer staging manual and stage grouping of lung cancer: quick reference chart and diagrams. Chest, 2011;139:183 - 9 .

14. Beltrami V, Gidaro G. Resection and reconstruction of the sternum: case report. Thorax, $1976 ; 31: 350-3$.

15. Frank JA, Ling A, PatronasNJ, Carrasquillo JA, Horvath K, Hickey AM, et el. Detection of malignant bone tumors: MR imaging vs scintigraphy. Am J Roentgenol, 1990;155:1043 - 8 .

16. Krishnamurthy GT, Tubis M, Hiss J, Blahd WH. Distribution Pattern of metastatic bone disease. A need for total body skeletal image. J Am Med Assoc, 1977; 237:2504 - 6.

17. Daldrup-Link HE, Franzius C, Link TM, Laukamp D, Sciuk J, Jürgens H, et el. Whole-body MR imaging for detection of bone metastases in children and young adults: comparison with skeletal scintigraphy and FDG PET. Am $J$ Roentgenol, 2001; 177:229 - 36.

18. Daliakopoulos SI, Klimatsidas MN, Korfer R. Solitary metastatic adenocarcinoma of the sternum treated by total sternectomy and chest wall reconstruction using a Gore-Tex patch and myocutaneous flap: a case report. J Med Case Reports, 2010; 4:75 - 82.

19. Cassinello EJ, González DABA, Rivera HF, Holgado ME. SEOM guidelines for the treatment of bone metastases from solid tumours. Clin Transl Oncol, 2012; 14:505. 